\title{
First report of basal stem rot and blight of yardlong bean (Vigna unguiculata subsp. sesquipedalis) caused by Athelia rolfsii in India
}

\author{
Abdulmajeed Sajeena ${ }^{1}$ (I) - Deepthi S. Nair ${ }^{2} \cdot$ Teja Sri Peteti $^{2} \cdot$ Jacob John $^{1} \cdot$ Bhadra Sudha $^{1}$. \\ Altharackal Vikraman Meera ${ }^{1}$
}

Received: 16 April 2020 / Accepted: 10 September 2020 / Published online: 24 September 2020

(C) Società Italiana di Patologia Vegetale (S.I.Pa.V.) 2020

Keywords Sclerotium rolfsii $\cdot$ Yard long bean $\cdot$ Basal stem rot and blight $\cdot$ rDNA $\cdot$ ITS

In January 2019, Yardlong bean [Vigna unguiculata (L.) Walp. ssp. sesquipedalis (L.) Verdc.] plants (var. NS 621) exhibited wilting, stem shredding, rotting and ultimately, drying symptoms at IFSRS, Karamana (08 $28^{\prime} 28^{\prime \prime}$ N, 76 $57^{\circ} 47^{\prime \prime}$ E). The disease incidence ranged between $15 \%$ to $30 \%$. At the stem base, pure white, fluffy, fan shaped mycelia were observed with mustard seed shaped sclerotia, which were detected up to $25 \mathrm{~cm}$ depth. The fungus was isolated following standard protocols. Cottony white, fluffy and silky mycelia were observed on potato dextrose agar (PDA) medium. The fungus completed its growth in Petri plates within 3 days of incubation. Irregular to circular, whitish (later tan coloured) sclerotia ( 0.5 to $2.1 \mathrm{~mm}$ ) were produced from 6th day of incubation. Hyaline and septate hyphae had the presence of clamp connections. The ITS (internal transcribed spacer) region of rDNA was amplified using the universal primers ITS4/ ITS5 (Kwon et al. 2014). Comparison of the sequence of amplicon using BLAST revealed $99.69 \%$ sequence similarity

Abdulmajeed Sajeena

sajeenamanjima@gmail.com

1 Integrated Farming System Research Station (IFSRS), Karamana, Thiruvananthapuram, Kerala Agricultural University, Kerala 695002, India

2 Department of Plant Pathology, College of Agriculture, Vellayani, Thiruvananthapuram, Kerala Agricultural University, Kerala 695002, India with four isolates of Athelia rolfsii (Athelia rolfsii (Curzi) C.C. Tu \& Kimbr.) with accession Nos. MN 121364, MG 836252, KY 216142 and HQ 420816, respectively. Based on morphological and molecular analyses, the fungus was identified to be A. rolfsii (syn. Sclerotium rolfsii; Mordue, 1974). The ITS sequence of the isolate was deposited in NCBI database (MN 696630.1). Twenty five, 2 week-old yardlong bean seedlings (var. NS 621) were inoculated with $5 \mathrm{~mm}$ culture discs of seven-day-old fungal colonies at stem base. The symptoms were exhibited on 20th day of inoculation. No symptoms were observed on uninoculated plants. The fungus was reisolated which exhibited the same morphological and cultural characters of A. rolfsii, thus proving Koch's postulates. To the best of our knowledge, this is the first report of basal stem rot and blight caused by $A$. rolfsii in yardlong bean in Kerala and elsewhere in India (Farr and Rossman 2020).

\section{References}

Farr DF, Rossman AY (2020) Fungal databases, U.S. National Fungus Collections, ARS, USDA. Retrieved may 29 from https://nt.ars-grin. gov/fungaldatabases/

Kwon JH et al (2014) First report of Sclerotium rot caused by Sclerotium rolfsii on Yacón in South Korea. Plant Dis 98(10):1443

Mordue JEM (1974) Corticium rolfsii. CMI Descript Patho Fungi Bac 41: $1-2$

Publisher's note Springer Nature remains neutral with regard to jurisdictional claims in published maps and institutional affiliations. 